\title{
Covid-19: Experts urge strategies to prevent further outbreaks in care homes
}

\author{
Shaun Griffin
}

London

With data showing that covid-19 outbreaks are occurring in $38 \%$ of care homes, a concerted effort is needed to prevent outbreaks in the rest, say experts.

Office for National Statistics data for the week ending 8 May 2020 showed that deaths from all causes in care homes fell by around a third, from 6409 the previous week to $4248 .{ }^{12}$ Deaths involving covid-19 as a proportion of all deaths in care homes continued to rise, however, to $39.2 \%$, from $37.8 \%$ in the previous week.

Speaking at a press briefing hosted by the Science Media Centre, David Spiegelhalter, chair of the Winton Centre for Risk and Evidence Communication at the University of Cambridge, said that the number of covid-19 deaths occurring in the community, mostly in care homes, was now around the same as in hospitals. This represented a "complete shift" from earlier in the pandemic, he said. "The displacement of normal [non-covid] hospital deaths into the community has continued as a result of the huge disruption to the health service," he noted.

Spiegelhalter estimated that over the past six weeks hospitals had essentially "exported" more than 8000 non-covid deaths back into the community.

Carl Heneghan, director of the Centre for Evidence-Based Medicine at the University of Oxford, said that covid related deaths were highly age dependent, with $73 \%$ occurring in people aged 75 or over. The situation was much more reassuring in under $45 \mathrm{~s}$, who represent only $1.1 \%$ of covid-19 deaths, he said.

Noting that $38 \%$ of care homes have covid-19 outbreaks, ${ }^{3}$ Heneghan said, "The key is what happens to the other $62 \%$. I'd be trying to do everything I can to ensure they don't have outbreaks. But the nature of this disease and the problem with the asymptomatic [transmission] is that when a single person walks from one home to another you'll get sporadic outbreaks.
If you infect one person in a home you could potentially infect multiple people very rapidly.

"The key now is a concerted effort to ensure the [remaining] $62 \%$ of homes do not join the others. Strategies to address this are needed as a matter of urgency."

Having covid-free carers living inside care homes and isolating people moving in or out of them were suggested as possible mitigating measures.

Giving evidence to the House of Commons Health and Social Care Committee on the same day, ${ }^{4}$ Martin Green, chief executive of Care England, said, "We had a policy of emptying hospitals and filling care homes, whereas other countries had a policy of taking people out of care homes, if there was difficulty isolating them." He noted, "There wasn't a recognition at the start of this pandemic ... that the most vulnerable people are in care homes," adding, "Planning did not comprehensively overview social care or understand that it was a very diverse system."

On the higher than expected number of deaths outside hospitals not being recorded as due to covid-19, Spiegelhalter said, "These questions cannot be answered by the data alone. We need surveys and retrospective analyses of the deaths in care homes that are not labelled as covid-19 to understand what led to them."

Office for National Statistics. Deaths registered weekly in England and Wales, provisional: week ending 8 May 2020. 19 May 2020. https://www.ons.gov.uk peoplepopulationandcommunity/birthsdeathsandmarriages/deaths/bulletins/ deathsregisteredweeklyinenglandandwalesprovisional/weekending8may2020.

2 Griffin S. Covid-19: "Staggering number" of extra deaths in community is not explained by covid-19. BMJ 2020;369:m1931. 10.1136/bmj.m1931 32404318

3 Public Health England. COVID-19: number of outbreaks in care homes-management information. May 2020. https://www.gov.uk/government/statistical-data-sets/covid-19number-of-outbreaks-in-care-homes-management-information\#history.

4 Health and Social Care Committee. 19 May 2020. Tuesday 19 May 2020 meeting. https: //www.parliamentlive.tv/Event/Index/5fbbebb5-b2e1-4339-aaeb-44a53aec56de.

Published by the BMJ Publishing Group Limited. For permission to use (where not already granted under a licence) please go to http://group.bmj.com/group/rights-licensing/ permissions 